\title{
El sistema financiero de Tailandia: liberalización, crisis e intervención (1980-2000)
}

DOI: $10.32870 /$ mycp.v4i12.128

Geneviève Marchini*

$\mathrm{E}$ 1 caso de Tailandia constituye un ejemplo extremo de las bondades aparentes e inmediatas asociadas a la liberalización y a la apertura externa del sistema financiero, y de los costos masivos que estos procesos pueden conllevar en el mediano plazo. Al igual que un gran número de economías emergentes, Tailandia emprendió la liberalización de su sistema financiero en la segunda mitad de la década de los 80, y acompañó estas reformas con una apertura muy amplia de la cuenta de capitales de la balanza de pagos. Ambos conjuntos de reformas, emprendidos en un contexto de rápida expansión de la economía tailandesa, contribuyeron a atraer hacia ésta masivos flujos de inversión externa, y elevaron aún más el ritmo de crecimiento del gasto y del producto interno.

A partir de 1996, algunos indicadores señalaban el deterioro de la situación financiera de las empresas y de las instituciones financieras tailandesas, así como su creciente vulnerabilidad ante una posible reversión de las entradas de fondos externos. En julio de 1997 la devaluación del baht tailandés inauguraba la "crisis asiática". Desde esta fecha, Tailandia ha experimentado una honda recesión, seguida de una recuperación económica, pero no ha logrado hasta la fecha resolver plenamente el problema de sobreendeudamiento de sus empresas ni

* Investigadora del Departamento de Estudios del Pacífico de la Universidad de Guadalajara. el de cartera vencida de bancos y compañías financieras.

En esta presentación de los aspectos financieros de la crisis tailandesa abordaremos, en primer lugar, los antecedentes de la liberalización financiera, es decir, el sistema financiero a inicios de los 80 y la crisis que sufrió hacia mitad de esta década; en un segundo momento, introduciremos el proceso de liberalización financiera y sus principales efectos, para luego analizar la crisis de 19961997 con las reformas y medidas de rescate posteriores. Concluiremos con un balance de los logros e insuficiencias de este proceso.

El sistema financiero antes de la liberalización

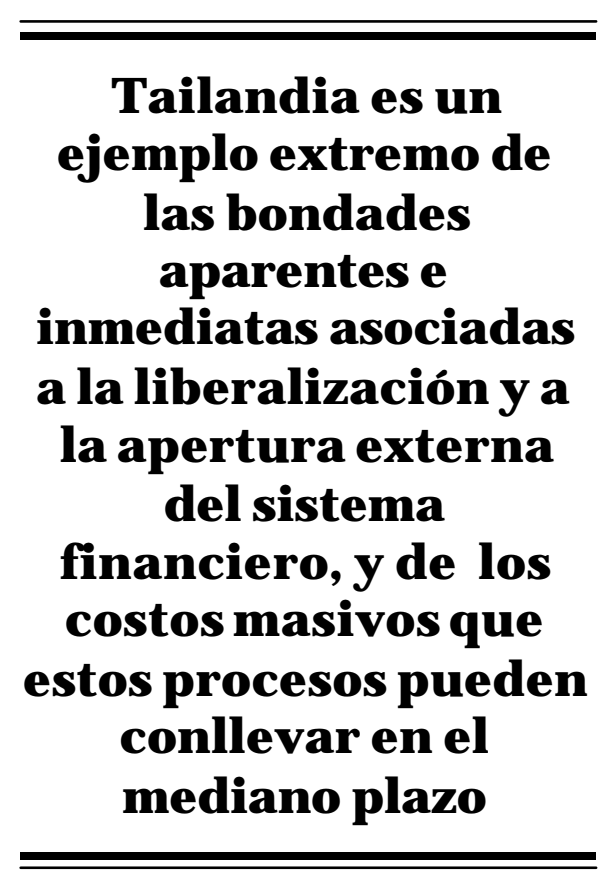

El sistema financiero tailandés era diversificado y desarrollado aún antes de las reformas, pues los activos financieros alcanzaban 98.9\% del PIB a fines de 1987, lo cual nos indica un sistema bastante profundo. El sistema financiero formal se componía de bancos comerciales, compañías financieras, compañías de crédito inmobiliario, diversas instituciones de fomento públicas, cooperativas de ahorro y casas de empeño; además existía un sistema financiero informal de cierta importancia.

Con más de $70 \%$ de los activos totales, los bancos comerciales dominaban netamente el sistema 
Cuadro 1

Títulos privados y públicos (miles de millones de baht, a fines de año)

\begin{tabular}{lrrrrrr}
\hline & 1989 & 1995 & 1996 & 1997 & 1998 & 1999 \\
\hline 1) En la bolsa de valores & & & & & & \\
Títulos privados & & & & & & \\
Valor de transacciones (anual) & 377.03 & $1,534.96$ & $1,303.14$ & 929.60 & 855.17 & $1,609.79$ \\
Número de compañís & 170 & 416 & 454 & 431 & 418 & 392 \\
Capitalización total (valor de mercado) & 659.50 & $3,564.57$ & $2,559.59$ & $1,133.34$ & $1,268.20$ & $2,193.10$ \\
Títulos públicos & & & & & & \\
Valor de transacciones (anual) & 38.83 & 0.00 & 0.00 & 0.00 & 0.00 & 0.00 \\
Capitalización total (a la par) & 198.39 & 43.91 & 17.99 & 13.72 & & \\
2) En mercados de mostrador & & & & & & \\
BSDC1 & & 0.24 & 1.81 & 0.12 & & \\
Valor de transacciones (anual) & & 1.51 & 71.32 & 71.60 & 37.53 & \\
Capitalización de mercado & & 1 & 3 & 3 & 5 & \\
Número de emisiones & & & & & & \\
BDC2 & & 51.53 & 200.60 & 103.54 & 72.09 \\
Valor de transacciones (anual) & & & & & & \\
\hline
\end{tabular}

1) BSDC = Bangkok Security Dealing Centre, Este mercado accionario de mostrador fue creado el 14 de noviembre 1995 y cerró en octubre de 1999.

2) $B D C=$ Bond Dealers Club, Este mercado de bonos de mostrador se creó en noviembre de 1994

Fuente: Bank of Thailand

financiero (véase cuadro 1). Sus actividades consistían esencialmente en recibir depósitos (a plazo o de ahorro) y en otorgar créditos, pero se responsabilizaban también de la mayoría de operaciones de cambio de divisas. A pesar del número elevado de bancos existentes en 1987, quince locales y catorce extranjeros, la estructura del sector era de tipo oligopólico, pues cuatro bancos locales, entre ellos uno propiedad del gobierno, el Krung Thai Bank, concentraban $63 \%$ de los activos. En razón de una serie de dispositivos legales que restringían sus actividades, los bancos extranjeros sólo representaban alrededor de 5\% de los activos del sistema bancario (Alba,
Hernández y Klingebiel 1999). La actividad de los bancos en general se hallaba sujeta a

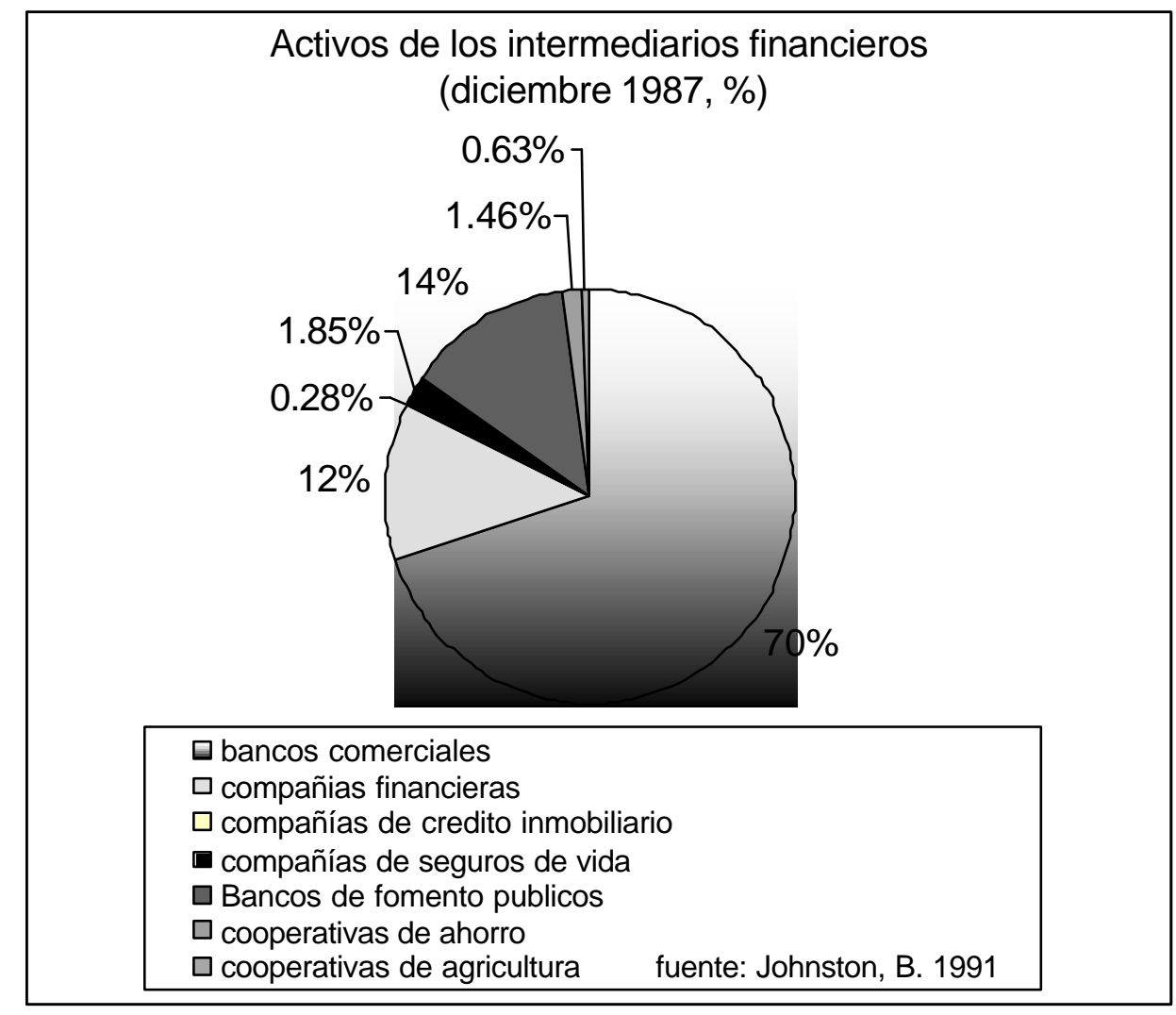


reglamentaciones como la imposición de topes a las tasas de interés, la obligación de orientar parte de sus créditos a sectores prioritarios (en especial, en el ámbito agrícola) y de constituir reservas legales en proporción de sus depósitos.

Las compañías financieras constituían el segundo intermediario en orden de importancia. Estas instituciones, más pequeñas y numerosas, operaban en un ambiente más competitivo y menos reglamentado que los bancos. Sus actividades se centraban, o bien en el financiamiento empresarial y en el crédito al consumo, en las operaciones con títulos, o combinaban ambos tipos de actividades (72 compañías en 1987). Estas operaciones estaban financiadas mediante la emisión de títulos a plazo (promissory notes) o crédito de otras instituciones financieras. El diferencial de reglamentación favorable permitió un rápido crecimiento del número de compañías financieras durante los 70: de 17 instituciones existentes en 1971 a 113 en 1979 (Johnston 1991), cifra que se redujo a 93 instituciones en 1987 (Alba, Hernández y Klingebiel 1999), después de la crisis que sufrió el sistema a mediados de los 80. Conjuntamente, las compañías financieras representaban (en 1987) $12 \%$ de los activos totales del sistema financiero.

Las demás instituciones importantes del sistema eran los bancos de fomento públicos enfocados a sectores específicos de la economía: el sector agrícola con el BAAC (Bank of Agriculture and Agricultural Cooperatives), la industria a través del Industrial Finance Corporation of Thailand, las pequeñas y medianas empresas industriales con el Small Scale Industries Financial Office y la vivienda mediante el Government Housing Bank. Estos intermediarios representaban conjuntamente $14 \%$ de los activos del sistema financiero. Éste contaba además con compañías de seguros de vida ( $1.85 \%$ de los activos) y otras instituciones de menor importancia macroeconómica, como las cooperativas de ahorro y las casas de empeño. El sistema se hallaba en parte bajo la supervisión exclusiva del Banco de Tailandia (banca comercial, compañías financieras, compañías de crédito inmobiliario), en parte bajo la supervisión conjunta del Ministerio de
Finanzas o de Industria y del banco central (instituciones de fomento), con la intervención adicional de otras entidades, como el Ministerio de Comercio para las compañías de seguros de vida. Esta fragmentación de la supervisión se mantiene hasta la actualidad.

\section{La crisis financiera de 1983-1987}

La crisis estalló en el segmento menos reglamentado y más expuesto al riesgo: las compañías financieras. Entre el último semestre de 1983, cuando se da el primer cierre de una institución y de dos filiales en razón de la magnitud de sus pérdidas, y 1986, 24 compañías financieras cierran sus puertas, produciéndose una pérdida de confianza del público en este segmento del sistema financiero y el consecuente retiro de fondos de los ahorradores, sustituidos por apoyos crediticios de la banca comercial y del Banco de Tailandia.

Simultáneamente, la posición financiera de los bancos locales se deterioraba: tanto las razones de capitalización promedio como las ganancias netas fueron declinando entre 1980 y 1986 , de $6.4 \%$ a $5.7 \%$ para las primeras, y de $25 \%$ a $7 \%$ del capital para las últimas. Por el contrario, la proporción de activos de mala calidad se elevaba, con una cartera vencida estimada de alrededor de $15 \%$ de los activos en 1987 (Johnston 1991).

La crisis forzó el banco central a intervenir. Esta intervención se hizo inicialmente a través de la concesión de préstamos blandos a las instituciones en problemas, tanto bancos como compañías financieras. A fines de 1986, cinco bancos recibían el apoyo del Banco de Tailandia y del Fondo para la Rehabilitación y el Desarrollo de las Instituciones Financieras (FRDFI), creado con este propósito en tanto entidad dependiente del banco central, con personalidad legal propia; dos bancos adicionales habían reportado dificultades financieras. En los casos más graves, el banco central tomó bajo su responsabilidad la administración de las instituciones, como en el caso del First Bangkok City Bank y del Sayam Bank, fusionado este último en 1987 con el 
Krung Thai Bank, de capital público (el cual recibía también el apoyo financiero del banco central), y adquirió paquetes accionarios a cambio de apoyo financiero. Las compañías financieras fueron apoyadas en primera instancia mediante un fondo establecido conjuntamente por el banco central y la Asociación Tailandesa de Banqueros, y luego, cuando las dificultades se hicieron más severas, a través del esquema del "barco de salvataje" ("lifeboat" scheme) que facilitó la reestructuración del sector a cambio de liquidez adicional (Johnston 1991).

La crisis financiera de mediados de los 80 ha sido atribuida a un conjunto de causas, tanto macro y microeconómicas, como de supervisión y reglamentación inadecuadas. El menor ritmo de crecimiento económico de la primera mitad de los 80 y las elevadas tasas de interés internas jugaron un rol de detonador al deteriorar la situación financiera de los deudores. El diagnóstico de la supervisión de las instituciones concluye que ésta era laxa, con reglamentaciones y estándares poco precisos e inferiores a las normas internacionales, que el banco central carecía de poderes en su misión de supervisor. Ahora bien, es en el funcionamiento interno de las instituciones financieras que cabe hallar algunas de las causas más profundas de la crisis: concentración de los préstamos alrededor de algunas empresas vinculadas con el banco, créditos a gerentes y accionistas, exposición excesiva al riesgo. Estos manejos reflejan a su vez la estrechez de los vínculos entre empresas financieras y no-financieras, así como el alto grado de concentración del capital en la economía tailandesa, en la cual se estima que a fines de 1987, diez familias controlaban $46.2 \%$ del valor capitalizado de las empresas que cotizan en la bolsa de valores, de los cuales casi $40 \%$ se hallaban en instituciones financieras y un poco más de $60 \%$ en empresas no-financieras (Claessens et al. 1999, citado por Alba et al. 1999).

En 1988 el sistema se hallaba todavía en precaria situación financiera, y ciertas instituciones todavía recibían apoyos públicos. Algunas reformas legales y regulatorias esenciales se habían introducido de manera muy reciente. Sin embargo, el marco macroeconómico estaba saludable, y dadas estas condiciones las autoridades decidieron liberalizar el sistema financiero y abrir la economía a los flujos transfronterizos de fondos.

\section{La liberalización financiera}

Las principales medidas de liberalización del sistema financiero interno comprendieron: el desmantelamiento de los topes de tasas de interés, tanto pasivas (1989-91) como activas (1992) para todos los intermediarios, y la eliminación de las reglamentaciones que limitaban las actividades permitidas a cada tipo de institución. Para la banca comercial, estas medidas incluyeron la relajación de las exigencias de crédito orientado al sector agrícola, la conversión del encaje legal en coeficiente de liquidez de $3 \%$ invertible en títulos públicos y, en 1992, la autorización de actividades de banca de inversión (emisión, suscripción y distribución de títulos de deuda, supervisión y colocación de fondos de inversión). Las compañías financieras recibieron la autorización de desempeñar las actividades de arrendamiento financiero (1991), de colocación de bonos públicos (1992) y de servicios de información financiera y de inversión (Alba et al. 1999).

La cuenta corriente y de capital de la balanza de pagos, ya relativamente abiertas en la década de los 80 , fueron liberalizadas respectivamente en 1990 y entre 1991-1993. Las medidas facilitaron la inversión extranjera directa en Tailandia y la inversión directa de nacionales en el exterior (1991 a 1994), así como la inversión de portafolio extranjera, en especial en fondos de inversión tailandeses. Sin embargo, la medida de mayor transcendencia fue la creación, en 1993, de las facilidades bancarias internacionales de Bangkok (Bangkok International Banking Facilities, BIBF). La creación de las BIBF respondía al objetivo explícito de transformar la plaza de Bangkok en un centro financiero internacional, siguiendo el ejemplo de Singapur y Hong-Kong. Los bancos establecidos bajo este régimen off-shore benefician con ventajas fiscales relevantes. Sus 
actividades se concentran en la captación de depósitos o préstamos en divisas provenientes del exterior y en préstamos en divisas a empresas tailandesas residentes o a empresas no-residentes, e incluyen también los préstamos sindicados, las operaciones sobre divisas y las actividades de banca de inversión (ibid.). Cabe subrayar que no solo bancos extranjeros sino también locales están establecidos bajo el esquema del BIBF.

\section{Los efectos de la liberalización}

En el ámbito financiero, la liberalización permitió cierta diversificación del sistema, con la participación de nuevos inversionistas institucionales, como los fondos de inversión y la dinamización de los mercados de títulos (cuadro 1). El ahorro financiero de los hogares creció de manera muy dinámica y se orientó cada vez más hacia las compañías financieras, cuya participación se elevó de $11.6 \%$ del total en 1991 a más de 17\% en 1996 (cuadro 2). Estas instituciones ganaron también posiciones en el mercado del crédito. Sin embargo, como lo veremos más adelante, la reforma propició un crecimiento poco sano tanto en estas instituciones como en el sistema bancario.

Cuadro 2

Ahorro de los hogares por tipo de institución

\begin{tabular}{|c|c|c|c|c|c|c|c|c|c|}
\hline & 1991 & 1992 & 1993 & 1994 & 1995 & 1996 & 1997 & 1998 & 1999 \\
\hline $\begin{array}{l}\text { Total de activos } \\
\% \text { del total }\end{array}$ & $1,738,515.6$ & $2,078,313.5$ & $2,429,918.4$ & $2,783,352.6$ & $3,319,517.3$ & $3,749,132.9$ & $4,016,832.4$ & $4,414,310 . \varepsilon$ & $4,187,300 . \bar{c}$ \\
\hline Bancos comerciales & 76.6 & 74.7 & 73.5 & 71.7 & 71.5 & 70.5 & 76.2 & 75.6 & 79.3 \\
\hline Compañías financieras & 11.6 & 14.1 & 15.4 & 17.2 & 17.2 & 17.6 & 10.0 & 8.7 & 3.0 \\
\hline Compañías de seguros de vida & 2.6 & 2.7 & 2.8 & 3.0 & 3.0 & 3.1 & 3.5 & 3.2 & 4.0 \\
\hline Compañías de cérdito inmobiliario & 0.1 & 0.2 & 0.2 & 0.2 & 0.2 & 0.2 & 0.1 & 0.1 & 0.1 \\
\hline Bancos de fomento públicos* & 9.0 & 8.3 & 8.1 & 8.0 & 8.2 & 8.6 & 10.2 & 12.3 & 13.6 \\
\hline
\end{tabular}

*Comprende: Govemment Saving Banks + Baac + Govemment Housing Bank

Fuente: Bank of Thailand

En el nivel macroeconómico la liberalización permitió financiar una elevación del gasto interno, y en especial de la inversión, que fomentó a su vez una aceleración del crecimiento económico. La inversión fija, que representaba $32.6 \%$ del PIB en 1988, creció a una tasa anual promedio de $10 \%$ entre 1991 y 1994 , y de $11 \%$ en 1994-1995, mientras el PIB lo hacía a un ritmo comprendido entre $8.5 \%$ y $9 \%$. Las exportaciones se expandieron a una tasa anual promedio superior a $14 \%$ entre 1991 y 1995, superada a partir de 1994 por el ritmo de crecimiento de las importaciones.

Este elevado ritmo de crecimiento económico fue financiado por masivas entradas de capitales y por un endeudamiento también masivo de las empresas y del sector privado tailandés en general. El marco macroeconómico favorecía en efecto la contratación de deuda externa: el tipo de cambio estaba fijado con relación a una canasta de monedas en la cual predominaba el dólar estadounidense y mostraba una gran firmeza. Esta aparente certidumbre cambiaria, aunada a unas tasas de interés reales internas (gráfica 1) superiores al costo del financiamiento en los mercados internacionales, propiciaron la toma de riesgos cambiarios de parte de los residentes. Los bancos y las compañías financieras fueron el principal conducto de los fondos hacia el sector real y, en consecuencia, las instituciones más afectadas por el estallido de la crisis en 1996-1997.

Entre 1988 y 1996 Tailandia ha recibido cantidades extraordinarias de fondos, que suman 100 billones de dólares y equivalen en promedio a una proporción anual de $9.4 \%$ del PIB (ibid), con máximos en 1990 y 1995 (más de $12 \%$ del PIB). El origen de los fondos se ha ido modificando a lo largo del período de la siguiente manera: la fracción intermediada por el sistema bancario y las compañías financieras se volvió mayoritaria después del establecimiento de las BIBF ( $60 \%$ de las entradas) y tendió a concentrarse en el corto plazo; la inversión 


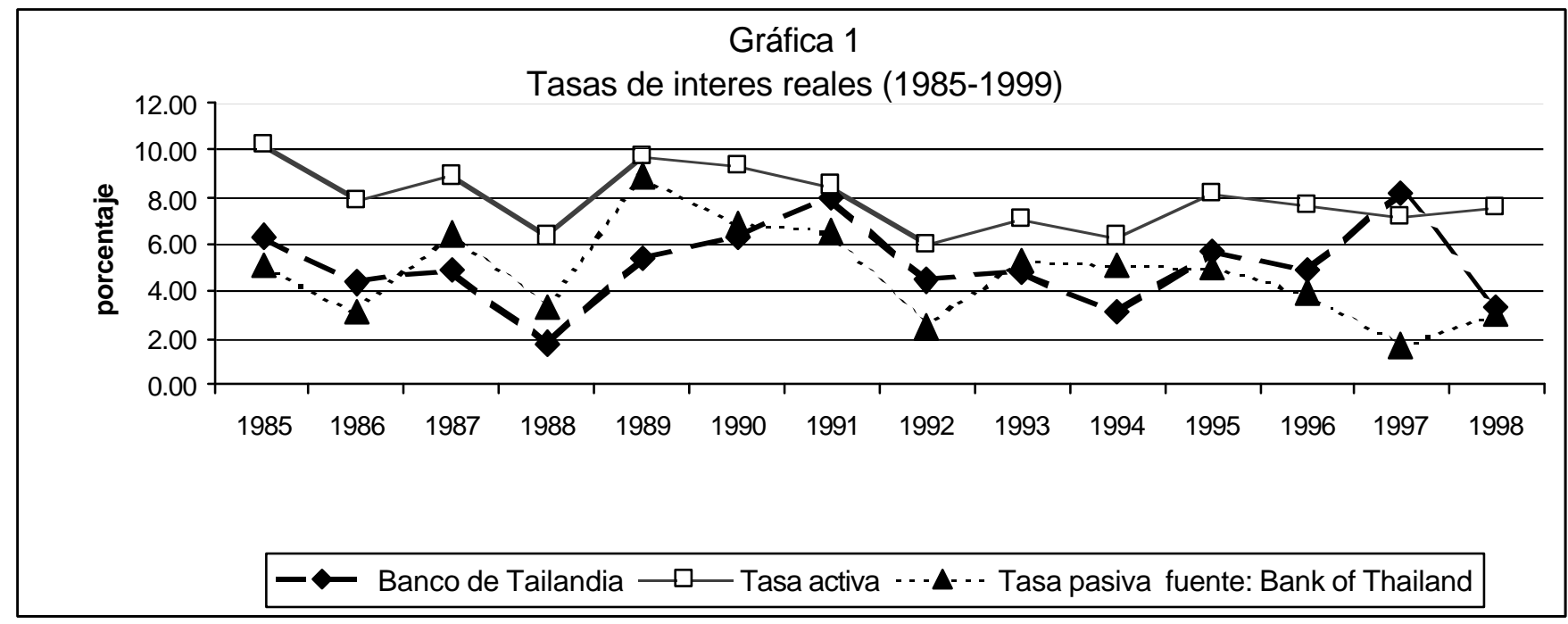

extranjera directa (IED) disminuyó su participación a la vez que se elevaba la de la inversión de portafolio. Ambas evoluciones tuvieron a su vez dos consecuencias que acrecentaron la vulnerabilidad externa de la economía: la acumulación de la deuda externa privada (gráfica 2), asociada a la elevación de la participación de la deuda bancaria (63\% del total en 1995), y la dependencia cada vez mayor del financiamiento de corto plazo, fácilmente reversible, de carácter tanto bancario (con una multiplicación por cuatro de la deuda privada de corto plazo) como no-bancario (flujos de portafolio).

En el ámbito interno, la gran disponibilidad de fondos conseguidos sobre la base del endeudamiento externo autorizó un auge del crédito: el otorgado por los bancos comerciales y las compañías financieras creció a ritmos que duplicaban o incluso triplicaban el ritmo de crecimiento del producto, elevándose la razón crédito/PIB de $64 \%$ en 1987 a $142 \%$ en 1996 (ibid.). La capacidad de las instituciones financieras para asignar correctamente el crédito, de por sí limitada como lo mostró la crisis de 1984-1987, fue obviamente rebasada: una proporción cada vez mayor de los fondos se orientó hacia sectores muy especulativos, como la inversión inmobiliaria, que constituía en 1996, según cifras oficiales, respectivamente $15 \%$ y $24 \%$ de la cartera de préstamos de los bancos y compañías financieras, o el crédito al consumo, mientras que la proporción recibida por los

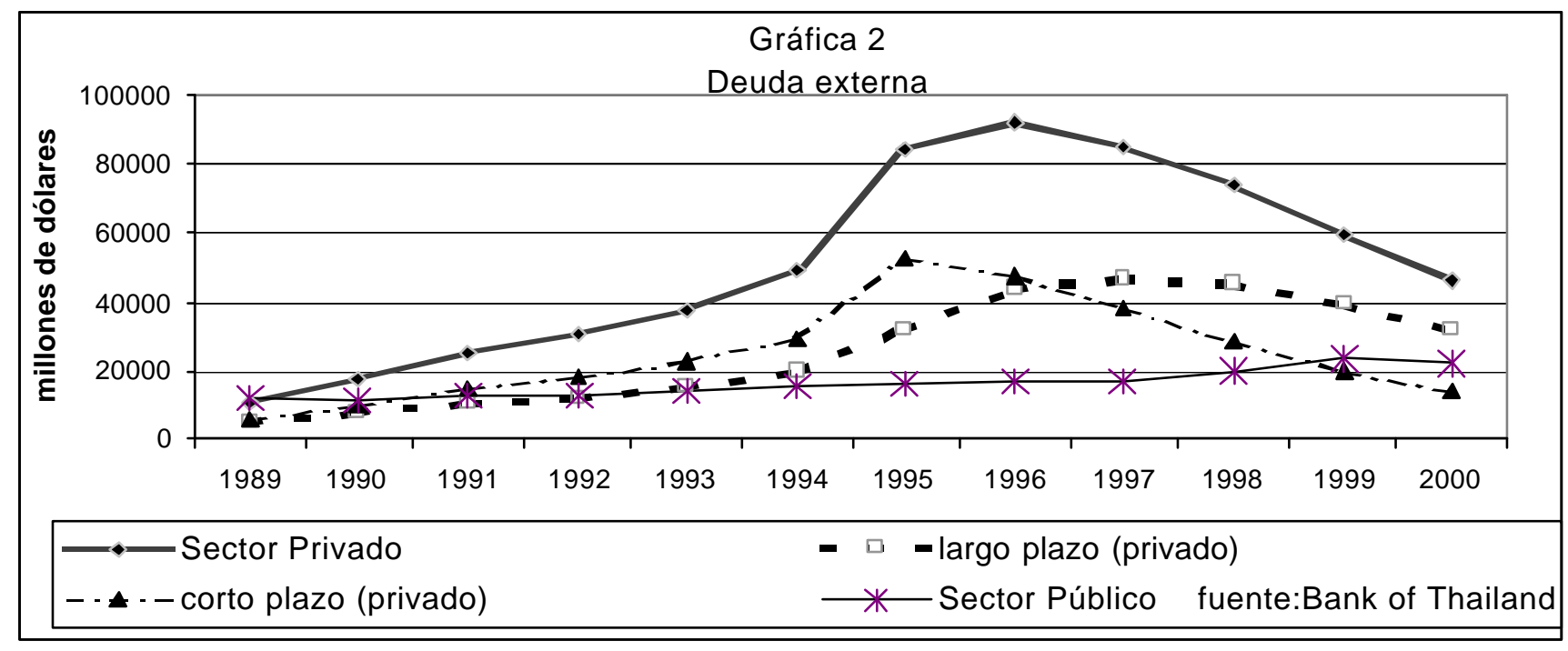


sectores de bienes comerciables se reducía. En consecuencia, a pesar del elevado nivel de crecimiento económico, que permitió mejorar los niveles de rentabilidad de empresas financieras y no-financieras, los intermediarios no lograron reducir el peso relativo de la cartera vencida, y desde 1994 ciertos indicadores tempranos señalaban inminentes problemas mayores. A finales de 1996, la crisis se inició, al igual que durante el episodio anterior, en el segmento más débil del sistema, las compañías financieras, que experimentaron una huída de depósitos. En 1997 el retiro masivo de fondos y la consecuente devaluación del bath generaron una crisis financiera de gran magnitud, en la cual se vieron involucrados todos los protagonistas del período de auge del crecimiento basado en el endeudamiento, tanto bancos como empresas nofinancieras.

\section{Intervención y reformas, 1997-2000}

La intervención de las autoridades ha buscado en primer lugar rescatar y sanear el sistema bancario y las compañías financieras, mediante el cierre de las instituciones insolventes y la recapitalización de los intermediarios viables.

La intervención se concentró inicialmente en el sector de compañías financieras: los préstamos blandos del FRDFI, que no lograron salvar a los intermediarios, fueron reemplazados por medidas mucho más drásticas, si bien aún aisladas. Así, a la vez que las autoridades establecían una protección para los depositantes, suspendían 16 compañías en junio de 1997, 42 en agosto, declarándose el cierre definitivo de la gran mayoría de estas instituciones en diciembre. En octubre del mismo año, en el marco del acuerdo con el FMI, se crearon dos nuevas estructuras encargadas respectivamente de rehabilitar el sector y de realizar los activos de empresas fallidas: la Autoridad de Reestructuración Financiera (Financial Restructuring Authority, o FRA) y la Corporación de Gestión de Activos (Asset Management Corporation, o AMC). En 1998, doce compañías financieras adicionales fueron intervenidas y fusionadas en el seno de un nuevo banco público, el Bank Thai.
La atención de las autoridades se volcó luego hacia el sistema bancario, cuyo tamaño implicaba un riesgo de carácter sistémico bastante mayor. La situación era apremiante: en efecto, después de la crisis cambiaria de julio, los bancos más débiles habían sido víctimas de retiros de depósitos, y, para el sistema en su conjunto, la cartera vencida se establecía, a fines de diciembre 1997, en un nivel superior a $22 \%$ del total de préstamos (FMI, 2000).

El enfoque aplicado por las autoridades ha combinado la intervención y la fusión de instituciones en dificultades con la recapitalización, vía el FRDFI y, para los bancos en mejores condiciones, a menudo mediante la entrada al capital de inversionistas extranjeros. En agosto de 1998, un "paquete" de medidas de reestructuración financiera anunciaba la creación de dos esquemas de financiamiento público destinados a facilitar la recapitalización bancaria, y autorizaba la creación de compañías de gestión de activos privadas. A mediados de 1999, las autoridades habían intervenido un total de seis bancos (de quince bancos locales). Como producto de la intervención pública, y de la eliminación de todo o parte del capital de las instituciones en dificultades, la participación de los bancos y de las compañías financieras en los activos del sistema financiero ha sido recortada drásticamente, creciendo en cambio la proporción en manos de instituciones públicas (gráfica 3).

Ahora bien, a pesar de estas medidas y de la recuperación de la economía tailandesa, la disminución del peso de la cartera vencida ha sido insuficiente para permitir a las instituciones recobrar la salud financiera. Desde un máximo de $47.7 \%$ de los préstamos en mayo de 1999 (Financial Times, 22/02/2001), la cartera de mala calidad se establecía todavía, en enero 2001, en $18.23 \%$ de los préstamos totales para los bancos privados y en $21.36 \%$ para los bancos propiedad del Estado, los cuales incluyen algunos bancos intervenidos (Bank of Thailand, 2001). Por esta razón, el nuevo gobierno tailandés dirigido por Thaksin Shinawatra decidió crear, en febrero de este año, una agencia 
Activos totales del sistema financiero

(diciembre 1999, en \%)

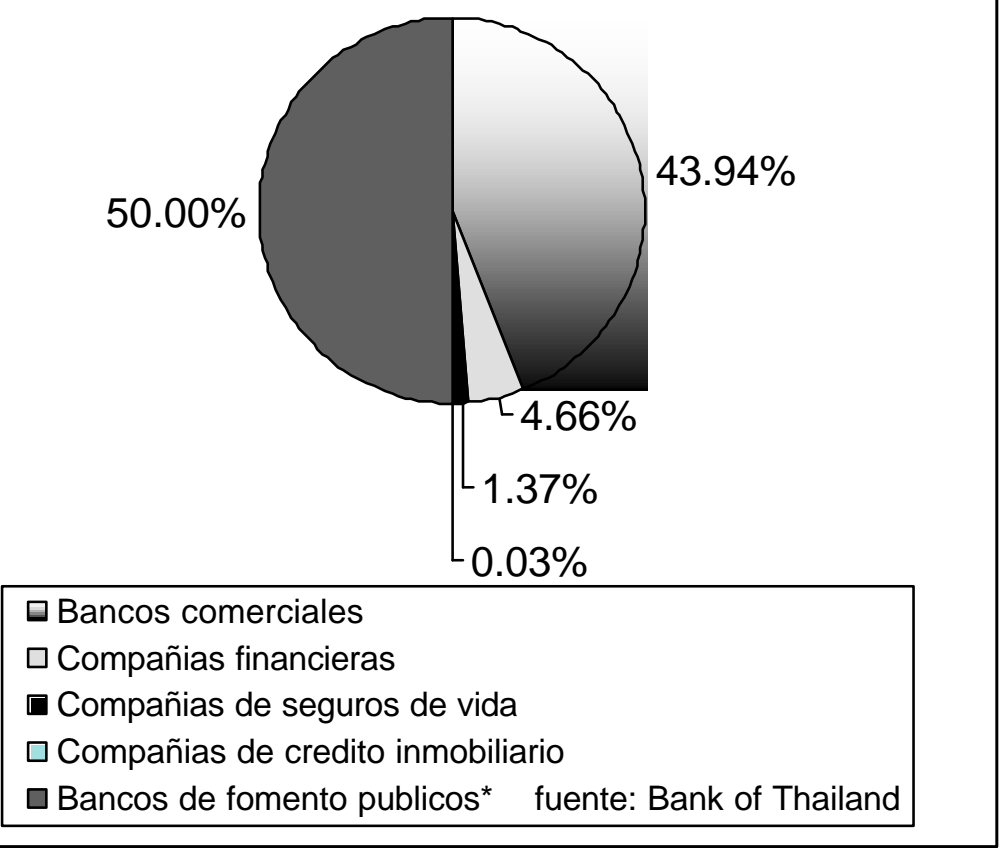

pública destinada a comprar los créditos de mala calidad del sistema bancario(Financial Times, 25/02/2001). Esta medida busca a la vez sanear el sistema bancario y acelerar la reestructuración de la deuda corporativa y la consolidación productiva, cuyos avances han sido lentos. Por esta razón, los activos adquiridos por la nueva entidad, llamada Thai Asset Management Corporation (TAMC), y creada para una duración de diez años, serán elegidos por los reguladores en la cartera de los bancos participantes (Financial Times, 12/03/2001) y deberán involucrar por los menos tres acreedores distintos (AsiaWise, 26/03/2001).

Paralelamente a estas medidas de emergencia, las autoridades tailandesas han emprendido reformas legales y regulatorias destinadas a eliminar las causas de la crisis y a evitar la reproducción futura de episodios similares. Esta medidas han comprendido una reestructuración interna del funcionamiento del banco central, cuya actuación ha sido analizada de manera crítica por el informe Nukul (Abe
Kiyoshi 1999). La reglamentación del sistema ha sido reforzada en marzo de 1998, en particular en cuanto a las normas de calificación de créditos y de provisionamiento, y los estándares de información. En julio de 1998 la definición de los activos de mala calidad era ajustada a los criterios internacionales (Vajragupta Yos y Pakorn Vichyanond 1999).

\section{Conclusión}

El fracaso de la liberalización financiera en Tailandia es notable tanto por los ingentes fondos externos recibidos y la amplia duración del episodio de entradas excesivas, como por la magnitud del posterior sobreendeudamiento de las empresas nofinancieras y de los créditos de mala calidad del sistema bancario. Las demás características de la crisis -utilización poco productiva de los recursos, excesiva inversión en sectores no-transables, políticas macroeconómicas y supervisión inadecuadas- son bastante similares a las observadas en otras economías en desarrollo de Asia o América Latina. Aparecen, sin embargo, algunas lecciones específicas de la experiencia de Tailandia. En primer lugar, subraya la importancia de la situación inicial de las instituciones financieras locales antes de la apertura; bancos poco saludables o mal preparados para asignar recursos siguiendo criterios de mercado especialmente vulnerables. En segundo lugar, $\mathrm{y}$ al igual que en el caso mexicano, demuestra el riesgo que conlleva un financiamiento externo concentrado en el corto plazo y combinado con un régimen de tipo de cambio fijo o semifijo. En tercer lugar, la combinación de apertura externa y liberalización interna casi simultáneas han ciertamente profundizado los excesos: por ejemplo, las elevadas tasas de interés reales internas, un fenómeno que suelen seguir la 


\section{liberalización, contribuyeron a elevar la demanda de crédito externo}

\section{Fuentes}

Abe, Kiyoshi (1999), "Financial crisis in Thailand", in Benton E. Gup (ed.), International banking crises: Largescale failures, massive government intervention, Quorum Books, 1999; Alba, Pedro, Leonardo Hernández y Daniela Klingebiel (1999): Financial liberalization and the capital account: Thailand 1988-1997, mimeo, Banco Mundial http://www.worldbank.org; AsiaWise Daily: http:// www.asiawise.com; Bank of Thailand: Statistics, http:// www.bot.or.th; Bank of Thailand: Thai financial institutions's recapitalization accomplished since January 1998 to Decembre 2000, http://www.bot.or.th; Bank of Thailand (2001): Communiqués $\mathrm{n}^{\circ} 36$ a 41, http:// www.bot.or.th; Claessens, Stijn, Simeon Djankov, Joseph P.H. Fan \& Larry H.P. Lang (1999): "Who controls East Asian corporations?", Policy Research Working Paper 1620, Banco Mundial; Financial Times (2000-2001): Artículos varios, edición en línea http://www.FT.com; Fondo Monetario Internacional (2000): Thailand: selected issues, IMF Staff country Report $\mathrm{n}^{\circ}$ 00/21, febrero, http:// www.imf.org; Johnston, R. Barry (1991): "Distressed financial institutions in Thailand: structural weaknesses, support operations, and economic consequences", in V. Sundararajan \& Tomás J.T. Baliño (ed.), Banking crises: cases and issues, F.M.I., 1991; Gup. Benton E. \& Doowoo Nam (1999): "Thailand: a tale of sustained growth and the collapse", in in Benton E. Gup (ed.), International banking crises: Large-scale failures, massive government intervention, Quorum Books, 1999; Vajragupta, Yos \& Pakorn Vichyanond (1999): "Thailand's financial evolution and the 1997 crisis", in Seiichi Masuyama, Donna Vandenbrink \& Chia Siow Yue (ed.), East Asia's financial systems - Evolution and crisis, NRI-ISEAS, 1999. 